\title{
Cesarean Section: Risk Factors Threatening the Health of the Mother, the Fetus and Newborn: A Grounded Theory Study
}

Mehrnush Mostafayi

Hamedan University of Medical Sciences

Behzad Imani ( $\sim$ behzadiman@yahoo.com )

Hamedan University of Medical Sciences

\section{Research Article}

Keywords: Cesarean section, Fetus, Newborn, Mother, Risk factors, Grounded theory

Posted Date: February 23rd, 2021

DOl: https://doi.org/10.21203/rs.3.rs-183497/v1

License: (c) (i) This work is licensed under a Creative Commons Attribution 4.0 International License.

Read Full License 


\section{Abstract}

Background: The excessive increase of cesarean section and the mother's attitude towards performing a cesarean section, despite the health-related complications for mother, fetus, and newborn, are a current global concern. Identifying risk factors can be effective in reducing the maternal and infant mortality. Therefore, the aim of this study was to explore risk factors threatening the health of the mother, fetus, and newborn in cesarean section.

Methods: The present study is a grounded theory which was performed from December 2019 to July 2020 in Fatemieh Hospital, Hamadan / Iran. Purposive and theoretical sampling was used to recruit Gynecologist, anesthesiologists, pediatricians, operating room and anesthesia experts, and midwives working in the operating room. In-depth, semi-structured interviews were conducted with 25 participants. Constant comparative analysis together with data collection. The analysis included open, axial, and selective coding to achieve data saturation. EQUATOR guidelines for qualitative research (COREQ) were applied.

Results: After analyzing the data, 8 sub-categories and 3 main categories were extracted. The three main themes extracted from the interviews were as follows: (1) Background factors with sub-categories "highrisk pregnancy, unusual fetus, and background risk factor ", (2) Environmental factors with sub-categories "poor operating room facilities, lack of proper electro-surgery safety measures, excessive workload" and (3) Human factors with sub-categories "lack of medical team skills and by individual error of the medical team ".

Conclusion: The results of this study provide an in-depth look at the risk factors threatening the health of the Mother, the Fetus and Newborn in cesarean section. According to the results of this study, obstetrics and gynecology operating rooms can prevent the occurrence of risks by using appropriate management methods and provide safe care to patients.

\section{Introduction}

Delivery is one of the most important health care services in all societies and should be supplied in an appropriate, low cost and with minimal physical and mental complications [1]. The cesarean section (Csection) as one of the delivery methods is no exclusion to this rule [2]. C-section is one of the most common surgical procedures that save mother and baby if medically indicated [3].It is classified based on the time of the surgical procedure in the elective $\mathrm{C}$-section planned by the woman and the obstetrician before delivery and the emergency $\mathrm{C}$-section occurring for reasons that occur suddenly in labor, such as Placenta previa, premature placental abruption, fetal distress [4].Medical indications for a C-section include previous cesarean section, dystocia, fetal distress, and abnormal presentation [5].Since there is currently no evidence that an increase in cesarean section translates into a decrease in maternal and perinatal mortality, the $\mathrm{WHO}$ has recommended that $\mathrm{C}$-section delivery rate for any region in the world should not exceed $10-15 \%$ in 1985 [6]. During the past few decades, the C-section delivery rate has been 
rising almost everywhere [7] and has become a pandemic phenomenon; however, almost one-third of women worldwide now give birth by $\mathrm{C}$-section [8].Causes that have been reported to be effective in this increase include multiple pregnancies, increased pregnancy complications, previous cesarean section, twin pregnancies, lack of progress in the delivery, breech presentation, maternal request, and increased induction of labor [9]. C-section like other surgical procedures, exposes women and infants to both shortand long-term health risks, potentially affecting the outcome of subsequent pregnancies [3]. The main complications of obstetrics and gynecology related to C-section include maternal death, postpartum infection, uterine rupture, bladder injury, abnormal placenta, ectopic pregnancy, stillbirth, and preterm delivery [10].Also, there are neonatal risks: babies born by repeated C-section are more likely to have respiratory troubles and need to be hospitalized in neonatal intensive care [11].Therefore, the $\mathrm{C}$-section should be performed only if clinically indicated, particularly given the growth in health care costs compared to vaginal delivery [12]. One of the important indicators of the level of health in any society is the rate of mother, fetus and newborn mortality improving the health of mothers and infants as two vulnerable groups as one of the goals of societal developments in the group is to pay attention to the quality of healthcare services. Given that several factors contributing to mother, fetus and newborn mortality, identifying risk factors can be effective in reducing their death rates.

\section{Materials And Methods}

\subsection{The purpose of the study}

The present study aimed to explore the risk factors threatening the health of the mother, fetus, and newborn during the cesarean section.

\subsection{The study design}

A qualitative study was carried on the framework of the Strauss's and Corbin's grounded theory. Among qualitative research methods, grounded theory is a form of natural field research that aims to deeply examine the actions, behaviors, opinions, and attitudes of individuals with groups when they occur in real life [13].

\subsection{Participants}

Gynecologist, anesthesiologists, pediatricians, operating room and anesthesia experts, and midwives working in the operating room were invited to participate in the study.

The study inclusion criteria were as follows: members of the surgical team, pediatrician, and midwives who had at least 5 years' experience in the operating room and were interested in participating in the study and sharing their experiences. The study exclusion criteria were specified as follows: having less than 5 years of work experience and those who were not interested in participating in the study. In this study, sampling was started based on purposive and continued using theoretical sampling. Initially, the names of experienced individuals were identified in consultation with the operating room manager.

After obtaining written consent and setting a time, individual interviews were conducted with the participants. 


\subsection{Data collection}

In this study, the data were collected through face-to-face semi-structured interviews using open-ended questions in a quiet room in the operating room setting from December 2019 to July 2020. At the beginning of the interview, the participants were asked this question: What are the risks that can threaten the health of mother, fetus, and newborn in the operating room? Other questions were asked according to the answer of each participant and the objectives of the research. All interviews with an average of one hour were conducted by the first author, and audio-recorded and transcribed word-for-word. Based on the results of data analysis from previous interviews, the next participant was chosen. At this stage, the researcher always tried to include people with different experiences in the study. To remove the ambiguities in the data and complete them, some participants were referred again and interviewed; therefore, 3 out of 25 participants were interviewed twice. Gradually, in theoretical sampling, the questions became more specific and the emphasis was on clarifying ambiguous points. Data collection was stopped after 25 participants were interviewed as data saturation was reached.

\subsection{Data analysis}

Based on Strauss and Corbin (2008) method, three main coding stages (open coding, axial coding, and selective coding) were used to analyze the data. In this method, data collection and analysis were performed continuously and data analysis was performed simultaneously with data collection [14].

\subsection{Rigor}

Four criteria of credibility, confirmability, reliability, and transferability were used. For validation, the researcher used Triangulation, Prolong engagement, Member check, and Persistent observation. For confirmability, the researcher tried to guarantee the validity of this research by preserving the documents related to the different stages of the research and reviewing the supervisor. For the reliability of the study, it was provided member check and was used for transferability by providing sufficient and detailed descriptions as well as using the maximum variety.

\section{Results}

In this study, the interviews were conducted were 25 participants, including Gynecologist, anesthesiologists, pediatricians, operating room and anesthesia experts, and midwives were interviewed. 1 participant was male and 24 were female. Participants' ages ranged from 29 to 47 years with an average age of 35 years. Participants' work experience of the participants was between 6 and 28 years with an average of 14.08 years (Table 1 ).

After coding by the first author, for each interview, 181 initial codes were extracted, and also after examining the similarities and removing the similar codes, 18 open codes were obtained. Then, by categorizing the related codes, 8 axial codes and 3 main themes of risk factors threatening the health of the mother, fetus, and newborn were obtained (Table 2).

\subsection{The concepts}




\section{3-1-1. Background factors}

The main category of background factors related to the threats to the mother and fetus and newborn includes three subcategories of high-risk pregnancy, unusual fetus, and background risk factor along with sub-categories of each of them, which are discussed below.

\section{3-1-1-1. High-risk pregnancy}

Placenta accrete. It is the most common type of placental abruption. Improper diagnosis of this complication can have dangerous adverse effects such as severe and uncontrollable bleeding, the need for blood transfusions, increased need for surgeries like hysterectomy, and increased mortality. " $A$ few days ago, during a night shift, we had a prima patient. When, the uterus was cut and the baby came out, we suddenly found a Placenta Accreta. Since, the residents do not usually conduct sonography for the primaries, before operation, they did not know that they had to reserve blood for her. The patient bled, I remember that we used 30 Langases and eventually led to a hysterectomy" (P1)

Deeply impacted fetal head. One of the causes of the difficult C-section is the condition in which the fetal head is packed in the birth canal and the position of the fetal head is inferior to the pelvis and normal delivery is not possible. This condition is associated with many maternal and fetal complications." It once happened to me that the baby was stuck in the birth canal, i.e., the mother had to have a cesarean section during a normal delivery. We had to have one of the residents put her hand in the vagina and put the fetal head in my hand, so that I could bring out the baby. "Suddenly I saw that the uterus was torn towards the bladder and the bladder was hurt, so we immediately called an urologist to come to repair the bladder" (P5)

Placental abruption. It is the separation of the placenta from its junction before the onset of labor and is one of the most common known causes of fetal mortality and in cases with delayed treatment, even the mother's health is endangered. "We had a 39-week-old baby whose mother had a placental abruption. The fetus had an ischemia. I went up to him and saw that his Apgar score was less than 6, so I quickly revived him and the baby was intubated" (P24)

\section{3-1-1-2. unusual fetus.}

Malpresentation. It occurs when the fetal presenting part is other than the fetal vertex. It may prolong the labor and make the mother doubly upset. "During the cesarean section, I took out a mother-dentist's twin babies. The first one was in cephalic position. Then, when I tried to remove the second baby, it was in breech. As I was pulling it out, it broke from the thigh so I heard a bang" (P5 (

"Once the position of the fetus in the uterus was transverse, the doctor made an incision in the uterus She tried to guide the fetus' head to make the cephalic position of the fetus easier to ejaculate. But she did not succeed. She had to make a more classic cut in addition to the first cut. The baby was difficult to remove it, but we faced a lot of bleeding" (P4) 
Macrosomia. It is defined as weight at birth in a term baby above 4,000 g. It is a common complication in midwifery and can have side effects on the mother and fetus at risk. "We had a macrosomic baby, it weighed about 5-6 kilos and it came out very hard. When we took it out, after a few minutes, we saw that his hand was completely motionless and dizzy. Later, when taking a graphic, they said that he had a dislocated shoulder while bringing out" (P2)

\section{3-1-1-3. Background risk factor.}

Maternal obesity. Various conditions, including the mother's physical condition, can affect surgical and anesthesia conditions. One of the high-risk conditions is maternal obesity, which can increase the risk of pregnancy complications. Perinatal complications such as preeclampsia and gestational diabetes are higher in obese mothers. "A patient was too fat with a lot of belly fat. The pressure we put on the fundus to get the baby out and help it to give birth was lost in the abdomen. Because of this, another colleague was pressing the mother's chest from anesthesia with the palm of her hand, such as CPR. When pressure was applied, suddenly mother's lower rib fractured' (P3)

Previous cesarean section. Due to the continuous increase in the rate of cesarean section, the number of people with a previous cesarean section has also increased. Possible consequences of recurrent previous cesarean sections such as hysterectomy, bladder and bowel injury, blood transfusion, infection, and abnormal placental implantation should be considered. "It was a patient with a history of previous cesarean section. While making the incision on the uterus, but I cut the baby's head. The mother later told me, and I said," because you had a cesarean section before and your uterus was very thin " (P5)

Intra-abdominal adhesions. Postoperative adhesions are one of the most important causes of postoperative complications such as intestinal obstruction, infertility, and intraoperative problems in a subsequent surgery. Adhesion during cesarean section increases the duration of surgery, intraoperative bleeding, maternal and fetal complications, and the need for assistance from other surgeons. "I was operating with one of the residents of the second year. When she gave the incision, I suspected that she had hit the intestine. At that moment, I did not say anything. She took the baby out and sew the uterus. She wanted to put the uterus and I said, "Let's check the intestine." We saw that it was perforated. We quickly called the general surgeon and the surgeon came and repaired the intestine" (P1)

\section{3-1-2. Environmental factors}

The main categories of environmental factors related to the threats to mothers, fetuses, and infants include the three subcategories of poor operating room facilities, lack of proper electro-surgery safety measures and excessive workload along with the sub-categories of each of them, which are discussed below.

\section{3-1-2-1. poor operating room facilities.}

Worn out equipment. The existence of defects and problems in the operation of the equipment can harm the patient. By contacting the medical equipment unit, their correct operation can be ensured. " $A$ few 
months ago, we had a baby. At birth, Apgar was a little low and the midwife put the baby under oxygen. A little later, she saw that the baby had apnea. We found out that the device was failed and the oxygen line was not working well, so we intubated the baby" (P24)

Shortage of proper equipment. Providing the necessary equipment and tools before the start of surgery is one of the factors that can ensure the safety of the patient during surgery. Also, in some surgeries, a special set of tools and equipment is needed to perform the surgery in its best form. "Yesterday, we had a patient. When she brought to recovery, we had low pulse oximeter. I used a pulse oximeter of another patient who was to be transferred to the ward. I said myself, "she is newly brought to recovery ward. I saw that her heart rate is going down and dropped to 48, 45 and 40. I asked for atropine, we talked to her, we gave her oxygen, and her heart rate went up" (P20)

\section{3-1-2-2. Lack of proper electro-surgery safety measures}

Accompanying jewelry. The patient's rings and other jewelry carry the risk of burns to the patient due to the creation of an alternative current due to the use of monopolar electrosurgery.

"We had a patient who came into the operating room with a bracelet. We explained to the patient that if you do not take them out, you will get burns. The patient was not satisfied to remove the bracelets. We asked her to sign the commitment form. Then, we covered the bracelets with glue and latex gloves to reduce the possibility of burns; we checked after the operation and saw that the patient's hand had a superficial burn" (P1)

Wetting the junction plate of the cutter during operation. Wetting the junction plate of the cutter during operation due to spillage of fluids or excessive sweating can cause burns to the patient. Burns and problems caused by the electro cautery can cause many problems for the patient and the surgical team. "We had a mother of twins, they have two amniotic sac as you know. After the babies were born, the operation field was so wet that it caused a piece of plate to get wet and separated from the mother's leg. After the operation, we saw that some part of the leg had burned" (P11)

\section{3-1-2-3. Excessive workload.}

Night shift fatigue. Night work can cause fatigue, negligence, and distraction at work by causing sleep deprivation. Fatigue significantly impairs the performance of the treatment team and seriously affects their ability to care for the patient effectively. "It happened to a midwife in a night shift several years ago. Now maybe the midwife was sleepy when she cut the umbilical cord in tangent to the skin. Actually, instead of cutting the umbilical cord from above the clamp, it was cut from under the clamp close to the skin. If we did not care the baby quickly, the baby would really die" (P2)

Staff shortage. The shortage number of personnel compared to the number of surgeries always leads to errors due to negligence, forgetfulness, or improper performance of tasks. "The number of personnel in the recovery ward is low and the recovery is very busy and the workload is very high. An anesthesia nurse with all those patients is really hard job. She must complete the whole files, additionally. This makes us 
unaware of the disease, once the uterus of one of the patients in Aton recovery, she was bleeding profusely, which we found out too late, and the mother returned to the operating room"(P11)

\section{3-1-3. Human Factors}

The main category of human factors related to the risks threating the health of mother, fetus, and newborn includes two subcategories of the lack of medical team skills and by an individual error of the medical team along with the sub-categories of each of them, which are discussed below.

\section{3-1-3-1. lack of medical team skills.}

Use of inexperienced personnel. Adequate experience and skills are very important factors contributing to the rate of human error. The probability of error in the performance of experienced personnel is generally much lower and novices are trying to make medical and pharmaceutical errors. "One night I was circular Nurse and the scrub nurse was a novice. After the baby came in, we saw that it smelled very bad. I found that the novice resident did not recognize the bladder tissue and cut it. We called in the midnight. An urologist came to repair" (P1)

Improper abdominovaginal delivery. During a cesarean section, an abdominovaginal procedure is performed to remove the fetus from the uterine incision in a low-lying position. In this procedure, the assistant inserts her hand through the vagina and places 2 or 4 fingers around the head, applying gentle pressure to the packed fetal head and pushes it up so that the surgeon can remove the head from the uterine incision. "A repeat cesarean section in which the mother herself was late to the hospital and her baby was in the birth canal. During the cesarean section, a novice person introduces her finger into the vagina and pushes the head up. And the pressure on the fontanelles was high, causing the baby's skull to break" (P14)

\section{3-1-3-2. by individual error of the medical team.}

Incorrect identification of mother and baby. Lack of proper identification of the patient is one of the cases that cause irreparable mistakes in the health care system. For this reason, patient authentication is an important factor in patient safety in the operating room. "I witnessed that a baby's bracelet was written incorrectly, and the parents would accept the baby's gender and that the baby is theirs; because they had changed the bracelets and they were suspicious" (P2)

Excessive hurry during surgery. There is always the possibility of error due to negligence, forgetfulness, or improper performance of tasks due to hurry and lack of time.

"Once, one of the surgeons was opening the mother's abdomen in a hurry. She punched the bladder with a scalpel so that all the urine came out" (P15)

"It was early in my job, when the scrub nurse wanted to cut the umbilical cord. She was in hurried so that he cut the baby's little finger. Fortunately one of the surgeons save it" (P1) 


\subsection{Conceptual framework}

Depicts the final conceptual framework constructed through the data analysis (Fig. 1).

\section{Discussion}

This study aimed to explore the risk factors threating maternal, fetal, and neonatal health during cesarean section. The findings of this study showed a framework of risk factors for maternal, fetal, and neonatal health that was extracted based on interviews conducted with members of the surgical team and pediatrician and midwives. According to our findings, one of the risk factors is the background factors, the sub-categories of which include high-risk pregnancy, abnormal fetus, and background risk factors. The results are consistent with those of the study of Garmi et al showing that pregnancy with the placenta accrete is prone to adverse consequences such as extensive bleeding and cesarean section hysterectomy [15]. In Krieger et al.'s study, obesity, previous cesarean section, hypertensive disorders, premature rupture of membranes, and gestational diabetes were identified as independent risk factors for SSI [16]. Tebeu et al. considered age under 17 years and over 39, nulliparity, and macrosomia as risk factors related to cesarean section [17]. But Van der Looven et al. concluded that Shoulder dystocia, macrosomia, maternal diabetes, instrumental delivery, and breech delivery are risk factors for factor neonatal brachial plexus palsy and Caesarean section appears as a protective [18]. In their study, Gungorduk et al. demonstrated that the presence of adhesions during the procedure was higher in the bladder injury group than the controls and concluded that a previous cesarean section was the most common risk factor for bladder injury during cesarean delivery and a big baby was an independent risk factor a Bladder injury during cesarean section [19]. However, Saban et al. found that adhesions from previous cesarean section did not appear to increase the risk of intraoperative organ damage and adverse neonatal outcomes [20].According to our findings, another risk factor is environmental factors, the subcategories of which include poor operating room facilities, lack of proper electro-surgery safety measures, and excessive workload along. In their study, Nemati et al. showed that the most effective environmental predisposing factors in the occurrence of staff error were related to the crowded operating room and a large number of surgeries. In the study, the most influential factor in the occurrence of errors from the employees' point of view is related to the shortage number of staff compared to the number of surgeries and considering heavy shifts and excessive overtime [21].In this regard, Cramer et al. showed that from the nurses' point of view, high workload, staff shortage, and a large volume of work are the three main factors contributing to the occurrence of medication errors [22]. In their study, Farzi et al. reported that high workload and unsafe work environment were identified as environmental factors causing the error. The most skill factor in error occurrence from the perspective of employees was unfamiliar with how to use the equipment. Employing inexperienced, non-academic, and non-specialized staff in surgery or different operating room positions and using new and modern equipment, regardless of staff training, can increase the incidence of errors in the operating room [23]. Mossadegh Rad et al. found that the patient was wet due to sweating and washing during the operation, incorrect position of the patient, unhealthy antistatic mattresses, and prolonged use of electrocautery were the most important causes of burns with cautery [24].According to our findings, another risk factor is human factors, the sub-categories 
of which include lack of medical team skills and by individual error of the medical team. In the metaanalysis performed by Berhan et al., 11 studies were reviewed in the abdominovaginal method, the probability of extension uterine incision was tripled, blood loss and transfusion were doubled, and the risk of postpartum endometritis was higher. In this meta-analysis, the method of removing the breech was introduced [25].Gorji et al. identified three important causes of operating room errors: negligence, equipment management problems, and inexperience and novice, respectively [26]. In a study conducted by Ronconi et al., high shift, less work experience, ignoring ethical issues, and feeling tired showed a significant relationship with the occurrence of medication error [27].

\subsection{Study limitations}

The sample of the research was limited to Fatemieh Hospital in Hamedan, which does not have enough representation and may limit the generalization of its results. Despite attempts to provide accurate interviewee experiences, this study may be biased by our interpretations.

\section{Conclusion}

In recent years, despite the efforts of the health care system, the rate of cesarean section has decreased, but the number of cesarean section $s$ in Iran in the first delivery is still higher, followed by repeated cesarean section is high. This surgery is associated with several risks for the mother and baby therefore, rational solutions must be considered to advance cesarean section with safe conditions, For example, proper evaluation of the mother before surgery and performing additional interventions for screws with special conditions, using capable and trained personnel, and providing equipment and supplies needed for surgery.

\section{Declarations}

\section{Ethics approval and consent to participate}

This study has been approved by the Ethical Committee of Research Vice-Chancellor of Hamadan University of Medical Sciences with the code of ethics IR.UMSHA.REC.1398.654 in accordance with the World Medical Association and the Declaration of Helsinki.

Informed consent was obtained from all subjects in the Ethics approval and consent to participate section.

\section{Consent for publication}

Not applicable.

\section{Competing interests}

The authors have declared that no potential conflicts of interest exist. 


\section{Funding}

this study was financially supported by the Hamadan University of Medical Sciences of Iran.

\section{Acknowledgements}

We would like to thank all the operating room staff, Gynecologist, and pediatricians of the hospitals affiliated with Hamadan University of Medical Sciences who participated in this research.

\section{References}

1. Ebrashy A-E, Kassab A, Nada A, Saleh W, Soliman A. Caesarean section in a university and general tertiary hospitals in Cairo; Egypt: rates, indications and limits. Kasr Al Aini Journal of Obstetrics and Gynecology (KAJOG). 2011;2(1):20-6.

2. Cunningham F, Leveno K, Bloom S, Spong C, Dashe J. Williams obstetrics, 24e: Mcgraw-hill; 2014.

3. Mascarello K, Horta B, Silveira M. Maternal complications and cesarean section without indication: systematic review and meta-analysis. Revista de saude publica. 2017;51:105. doi.org/10.11606/S1518-8787.2017051000389

4. Pillitteri A. Maternal and child health nursing 7th ed. wolter kluwer, California2015. $654 \mathrm{p}$.

5. Fawzy A, Sweilam M, El-Agwany A, Hassan E, Moustafa A, Fawzy D. Pulling Down the Curtain on Unnecessary Caesarean Section: Shatby Maternity University Hospital Experience in Alexandria with Systematic Literature Review. Women's Health Gynecology. 2016;2(2):21-6.

6. WHO. WHO statement on caesarean section rates. World Health Organization; 2015.

7. Boerma T, Ronsmans C, Melesse D, Barros AJ, Barros F, Juan L, et al. Global epidemiology of use of and disparities in caesarean sections. The Lancet. 2018; 392(10155):1341-8. doi.org/10.1016/S0140-6736(18)31928-7

8. Hamiton B, Martin J, Osterman M. Births: Preliminary Data for 2015. Natl Vital Stat Rep. 2016;65(3):1-15.

9. Hamilton B, Martin J, Ventura S. Births: preliminary data for 2012. National vital statistics reports. 2013;62(3):1-20.

10. Franchi M, Raffaelli R, Baggio S, Scollo M, Garzon S, Laganà A, et al. Unintentional transvesical caesarean section: incidence, risk factors, surgical technique and post-operative management. European Journal of Obstetrics \& Gynecology and Reproductive Biology. 2019;236:26-31. doi.org/10.1016/j.ejogrb.2019.02.023

11. Arlier S, Seyfettinoğlu S, Yilmaz E, Nazik H, Adıgüzel C, Eskimez E, et al. Incidence of adhesions and maternal and neonatal morbidity after repeat cesarean section. Archives of gynecology and obstetrics. 2017;295(2):303-11. doi.org/10.1016/j.ejogrb.2015.06.009

12. Cegolon L, Mastrangelo G, Campbell O, Giangreco M, Alberico S, Montasta L, et al. Length of stay following cesarean sections: A population based study in the Friuli Venezia Giulia region (North- 
Eastern Italy), 2005-2015. PloS one. 2019;14(2):e0210753. doi.10.1038/s41598-019-55389-z

13. Speziale H, Streubert H, Carpenter D. Qualitative research in nursing: Advancing the humanistic imperative: Lippincott Williams \& Wilkins; 2011.

14. Corbin J. Strauss.(2008). Basics of qualitative research. Techniques and Procedures for.

15. Garmi G, Salim R. Epidemiology, etiology, diagnosis, and management of placenta accreta. Obstetrics and gynecology international. 2012;2012.

16. Krieger Y, Walfisch A, Sheiner E. Surgical site infection following cesarean deliveries: trends and risk factors. The Journal of Maternal-Fetal \& Neonatal Medicine. 2017;30(1):8-12. doi.10.3109/14767058..2016.1163540

17. Tebeu P, Mboudou E, Halle G, Kongnyuy E, Nkwabong E, Fomulu J. Risk factors of delivery by caesarean section in Cameroon (2003-2004): a regional hospital report. ISRN obstetrics and gynecology. 2011;2011. doi:10.5402/2011/791319

18. Van der Looven R, Le Roy L, Tanghe E, Samijn B, Roets E, Pauwels N, et al. Risk factors for neonatal brachial plexus palsy: a systematic review and meta-analysis. Developmental Medicine \& Child Neurology. 2020;62(6):673-83. doi.org/10.1111/dmcn.14381

19. Gungorduk K, Asicioglu O, Celikkol O, Sudolmus S, Ark C. latrogenic bladder injuries during caesarean delivery: a case control study. Journal of Obstetrics and Gynaecology. 2010;30(7):667-70. doi.org/10.3109/01443615.2010.486086

20. Saban A, Shoham-Vardi I, Yohay D, Weintraub A. Peritoneal adhesions do not increase intra-operative organ injury or adverse neonatal outcomes during a repeated cesarean delivery. Archives of Gynecology and Obstetrics. 2020;302(4):879-86.

21. Nemati M, Mohammadzadeh Zarnakesh Sh, Ebrahimi Abyaneh E. Investigating the cases and influencing factors of errors in the operating room: staff perspective. Journal of Islamic Azad University. 2018;20(2):153-61.

22. Cramer $\mathrm{H}$, Pohlabeln $\mathrm{H}$, Habermann M. Factors causing or influencing nursing errors as perceived by nurses: findings of a cross-sectional study in German nursing homes and hospitals. Journal of Public Health. 2013;21(2):145-53.

23. Farzi S, Alimohammadi N, Moladoost A. Medication errors by the intensive care units' nurses and the Preventive Strategies. Anesthesiology and pain. 2016;6(4):33-45.

24. Mosadeghrad A, Khalaj F. The impact of quality managnt on reducing electrocautery burn. Journal of Hospital. 2020;19(1):81-8.

25. Berhan Y, Berhan A. A meta-analysis of reverse breech extraction to deliver a deeply impacted head during cesarean delivery. International Journal of Gynecology \& Obstetrics. 2014;124(2):99-105. doi.org/10.1016/j.ijgo.2013.08.014

26. Gorji H, Ravaghi H, Pirouzi M, Mansourzade A. Utilizing Integrated Prospective and Retrospective Risk Analysis Method on General Processes Patient Flow in Operating Room inSeyed Alshohada Hospital in Semirom, Iran. Health Inf Manage. 2013;10(3):488-97. 
27. Ronconi L. Derecho a la salud: un modelo para la determinación de los contenidos mínimos y periféricos. Salud colectiva. 2012;8:131-49.

\section{Tables}

Table 1.Participant characteristics. 


\begin{tabular}{|c|c|c|c|c|}
\hline No & Age (years) & Sex & Level of Education & Experience (year) \\
\hline p1 & 40 & female & Surgical technologist & 17 \\
\hline p2 & 45 & female & Surgical technologist & 23 \\
\hline p3 & 31 & female & Surgical technologist & 10 \\
\hline p4 & 34 & female & Surgical technologist & 10 \\
\hline p5 & 35 & female & Gynecologist & 7 \\
\hline p6 & 29 & Female & Nurse Anesthetist & 6 \\
\hline p7 & 47 & Female & Surgical technologist & 28 \\
\hline p8 & 47 & Female & Nurse Anesthetist & 28 \\
\hline p9 & 47 & Female & Surgical technologist & 27 \\
\hline p10 & 47 & Female & Anesthesiologist & 27 \\
\hline p11 & 32 & Female & Surgical technologist & 9 \\
\hline p12 & 40 & Female & Anesthesiologist & 20 \\
\hline p13 & 40 & Female & Surgical technologist & 20 \\
\hline p14 & 28 & Female & obstetrician & 6 \\
\hline p15 & 30 & Female & Surgical technologist & 10 \\
\hline p16 & 40 & Female & Anesthesiologist & 12 \\
\hline p17 & 45 & Female & Surgical technologist & 23 \\
\hline p18 & 35 & Female & Surgical technologist & 10 \\
\hline p19 & 45 & Female & Anesthesiologist & 15 \\
\hline p20 & 32 & Female & Nurse Anesthetist & 8 \\
\hline p21 & 31 & Female & Nurse Anesthetist & 7 \\
\hline p22 & 28 & Female & obstetrician & 6 \\
\hline p23 & 35 & Female & Surgical technologist & 9 \\
\hline p24 & 40 & male & pediatrician & 8 \\
\hline p25 & 36 & Female & Gynecologist & 6 \\
\hline
\end{tabular}

Table 2. Risk factors threatening the health of mother, fetus and newborn in cesarean section. 


\begin{tabular}{|c|c|c|}
\hline placenta accreta & high-risk pregnancy & \multirow{8}{*}{$\begin{array}{l}\text { background } \\
\text { factors }\end{array}$} \\
\hline deeply impacted fetal head & - & \\
\hline placental abruption & • & \\
\hline malpresentation & \multirow[t]{2}{*}{ unusual fetus } & \\
\hline macrosomia & & \\
\hline maternal obesity & \multirow[t]{3}{*}{ background risk factor } & \\
\hline previous cesarean section & & \\
\hline intra-abdominal adhesions & & \\
\hline worn out equipment & \multirow{2}{*}{$\begin{array}{l}\text {. poor operating room facilities } \\
\text {. }\end{array}$} & Environmental \\
\hline shortage of proper equipment & & factors \\
\hline accompanying jewelry & . lack of proper electro-surgery & \\
\hline $\begin{array}{l}\text { wetting the junction plate of the } \\
\text { cutter during operation }\end{array}$ & - $\quad$ safety measures & \\
\hline night shift fatigue & \multirow[t]{2}{*}{ excessive workload } & \\
\hline staff shortage & & \\
\hline use of inexperienced personnel & \multirow{2}{*}{. lack of medical team skills } & Human \\
\hline improper abdominovaginal delivery & & Factors \\
\hline $\begin{array}{l}\text { incorrect identification of mother and } \\
\text { baby }\end{array}$ & \multirow{2}{*}{$\begin{array}{l}\text { by individual error of the } \\
\text { medical team }\end{array}$} & \\
\hline excessive hurry during surgery & & \\
\hline
\end{tabular}

\section{Figures}




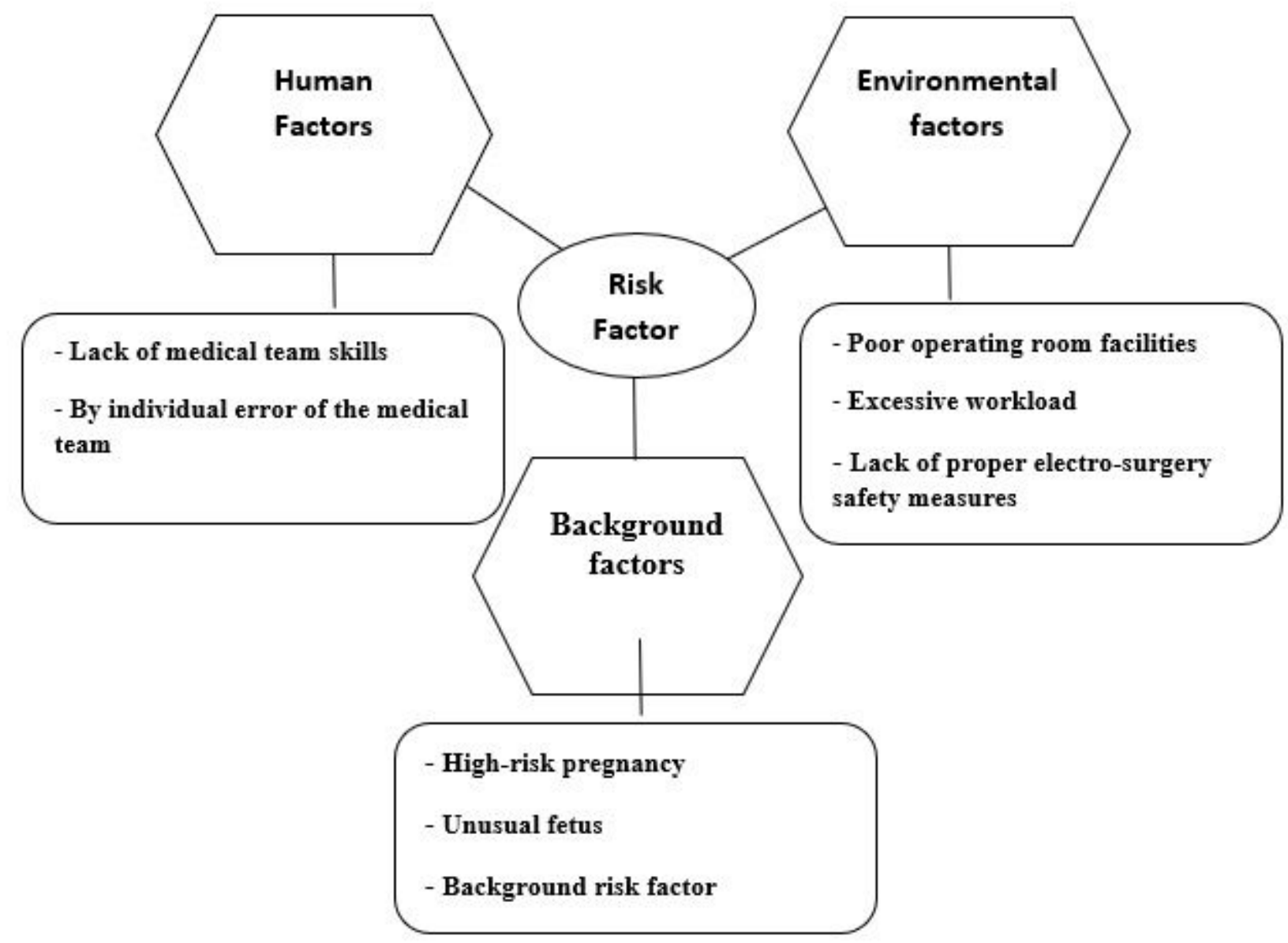

Figure 1

risk factors threatening the health of mother, fetus and newborn in cesarean section 